\title{
Correction to: Tibiofemoral subluxation in the coronal plane does not affect WOMAC and KOOS after total knee arthroplast
}

\author{
Mehmet Ozbey Buyukkuscu ${ }^{1}$ (D) Abdulhamit Misir ${ }^{1} \cdot$ Akay Kirat $^{2} \cdot$ Kutalmis Albayrak $^{3} \cdot$ Kerem Sencan $^{4}$. \\ Ismet Yalkin Camurcu ${ }^{5}$. Sukru Sarper Gursu ${ }^{4}$
}

Published online: 29 May 2020

(c) European Society of Sports Traumatology, Knee Surgery, Arthroscopy (ESSKA) 2020

\section{Correction to: \\ Knee Surgery, Sports Traumatology, Arthroscopy \\ https://doi.org/10.1007/s00167-020-06047-9}

Unfortunately, the co-author name was published as "A. Hamit Misir" instead of "Abdulhamit Misir'" in the original publication. The correct version of author name is updated here.

The original article has been corrected.

Publisher's Note Springer Nature remains neutral with regard to jurisdictional claims in published maps and institutional affiliations.

The original article can be found online at https://doi.org/10.1007/ s00167-020-06047-9.

Mehmet Ozbey Buyukkuscu

o.z.b.e.y@hotmail.com

1 Department of Orthopaedics and Traumatology,

Gaziosmanpasa Training and Research Hospital, Karayolları

Mahallesi, Istanbul 34255, Turkey

2 Department of Orthopaedics and Traumatology, Dortyol State Hospital, Hatay 31670, Turkey

3 Department of Orthopaedics and Traumatology, Haseki Sultangazi Training and Research Hospital, Istanbul 34270, Turkey

4 Department of Orthopaedics and Traumatology, Health Science University Baltalimani Bone Diseases Education and Research Hospital, Istanbul 34467, Turkey

5 Department of Orthopaedics and Traumatology, Faculty of Medicine, Erzincan University, Erzincan 24030, Turkey 